A collaboration between the JAOA and the American Association of Colleges of Osteopathic Medicine (AACOM) to recruit, peer review, publish, and distribute research and other scholarly articles related to osteopathic medical education.

\title{
JAOA/AACOM
}

\section{Interprofessional Education on Medication Adherence: Peer-to-Peer Teaching of Osteopathic Medical Students}

Emily Chan, PharmD, BCACP; Shadi Doroudgar, PharmD, BCPS, BCGP, BCPP; Jimmy Huang, PharmD (Candidate); Eric J. Ip, PharmD, BCPS, CSCS, CDE

From Touro University College of Pharmacy in Vallejo, California.

Financial Disclosures: None reported.

Support: Supported by the 2018 Touro University California Intramural Research Award Program Grant.

Address correspondence to Emily Chan, PharmD, BCACP, Nebraska Medicine, 988125 Nebraska Medical Center, Omaha, NE 68198-1090.

Email: emchan@nebraskamed.com

Submitted

September 8, 2019; revision received

December 21, 2019; accepted January 27, 2020.
Context: Medication nonadherence is an important barrier to achieving optimal clinical outcomes. Currently, there are limited data on methods used to train medical students about medication adherence.

Objective: To evaluate the knowledge, confidence, and attitudes of first-year osteopathic medical students before and after a 30-minute peer-to-peer medication adherence education program led by a third-year pharmacy student.

Methods: All first-year medical students from Touro University California College of Osteopathic Medicine were invited to participate in 1 of 3 medication adherence educational sessions held in May 2019. A third-year pharmacy student who received training from Touro University California College of Pharmacy faculty served as the peer educator. Each session took approximately 1 hour to complete. The session included a preprogram survey, a 30-minute program, and a postprogram survey. Survey items included demographics; medication adherence knowledge, confidence, and attitudes; and attitudes toward the peer-to-peer educational format. Statistical comparisons of preprogram and postprogram knowledge, confidence, and attitudes were made using a paired $t$ test, the McNemar test, and the Wilcoxon signed-rank test. $P<.05$ was considered statistically significant. A sample size calculation was performed using mean knowledge scores to determine whether the study achieved $80 \%$ power.

Results: Twenty-three students participated in the study. Medication adherence knowledge scores improved after the program (17.4 [77.4\%] vs 9.98 [92.2\%]; $P<.001)$. Confidence scores also improved for all 7 survey items $(P<.001)$. Medical students had more positive attitudes toward medication adherence after the program, with 8 of 10 survey items in this domain showing improvement. Most students had a positive attitude toward the peer-to-peer educational format. All participants reported that they would implement the medication adherence skills learned at the program with future patients.

Conclusion: A 30-minute peer-to-peer program led by a pharmacy student improved first-year medical students' knowledge, confidence, and attitudes with regard to medication adherence and provided an effective format to enhance interprofessional learning and collaboration.

J Am Osteopath Assoc. 2020;120(4):218-227

doi:10.7556/jaoa.2020.038

Keywords: interprofessional education, medication adherence, peer-to-peer education, pharmacology 
$\mathrm{M}$

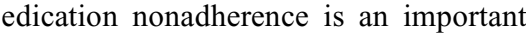
barrier to achieving optimal clinical outcomes for patients, especially those with long-term chronic diseases such as hypertension, asthma, and diabetes mellitus. ${ }^{1}$ Medication nonadherence accounts for about 1 in 3 medication-related hospitalizations and 125,000 deaths per year in the United States. ${ }^{2,3}$ Patients may be nonadherent to their medications because of cost, adverse effects, forgetfulness, and medication regimen complexity. ${ }^{3}$ Health care professionals are in a position to assess, identify, and solve these gaps in adherence so that patients can achieve the maximum benefit from their medications.

Previous literature suggests that physicians do not adequately assess patients' medication adherence or appropriately provide counseling on adherence strategies. ${ }^{4-6}$ One study at the Emory University School of Medicine showed that providing a medication counseling workshop to internal medicine residents was effective in improving self-reported confidence and behaviors. The workshop resulted in significant increases in desirable behaviors, including assessing patients' understanding of how to take their medications and barriers to adherence. Some workshop topics included factors affecting adherence, the role of health literacy in medication use, and prescribing in a way that promotes adherence. ${ }^{7}$ However, this training could ideally be incorporated earlier, such as during the didactic portion of the medical school curriculum, before the majority of patient care activities take place.

To date, studies on training students about medication adherence have been limited to medical, nursing, or pharmacy students. Much of the current literature for medical and nursing students assesses the impact of pill-taking exercises on empathy. ${ }^{8-11}$ While teaching empathy is important for understanding medication adherence, students training to become health care professionals should also be equipped with the tools to identify and address nonadherence. Pharmacists play an expanded role in medication management, and formal medication adherence training is a standard part of pharmacy school curricula. ${ }^{12}$ Therefore, pharmacy students are in a unique position to enhance interprofessional education (IPE) by teaching students in other health care disciplines about medication adherence.

According to the Center for the Advancement of Interprofessional Education, IPE "enables two or more professions to learn with, from, and about each other to improve collaborative practice and quality of care."13 One example of IPE includes the concept of peer-to-peer education. A study by Lipton et $\mathrm{al}^{14}$ demonstrated the effectiveness of a peer-to-peer education program in which pharmacy students taught medical students, nursing students, and medical residents about navigating Medicare Part D prescription drug benefits. The purpose of the present study was to assess the medication adherence knowledge, confidence, and attitudes of medical students before and after a peer-to-peer educational program led by a third-year pharmacy student.

\section{Methods}

This prospective, descriptive study took place on the Touro University California (TUC) campus. This study was approved by the TUC institutional review board, and informed consent was obtained from all participants.

All first-year medical students at TUC College of Osteopathic Medicine were invited to participate in 1 of 3 sessions held at the end of their first didactic year in May 2019. Participants were recruited by verbal announcements during didactic lectures, emails, and flyers posted around classrooms. Participants were notified that upon study completion, they would each receive a $\$ 10$ gift card. Each session lasted about an hour and included 3 parts: (1) a paper preprogram survey (15 minutes), (2) the program (30 minutes), and (3) a paper postprogram survey (15 minutes).

\section{Surveys}

The preprogram survey encompassed 4 sections: demographics, knowledge, confidence, and attitudes on medication adherence. The postprogram survey also encompassed 4 sections, but the demographics section was replaced by questions related to attitudes toward 
the interprofessional peer-to-peer teaching format. The preprogram and postprogram survey questions were adapted from surveys in previously published tools and educational studies. The knowledge questions were multiple-choice format and used with permission from the AMA Steps Forward (American Medical Association) Medication Adherence module quiz. ${ }^{15}$ Confidence and attitude questions were adapted from a study evaluating the effectiveness of a medication adherence workshop for medical residents. ${ }^{7}$ Attitude questions on the peer-to-peer educational format were adapted from the aforementioned study evaluating the effectiveness of a peer-to-peer instructional format covering Medicare Part D. ${ }^{14}$ This survey instrument included questions on a 4-point scale for confidence ( $1=$ not confident, $4=$ very confident) and attitudes ( $1=$ strongly disagree, $4=$ strongly agree).

\section{Educational Intervention}

A third-year pharmacy student served as the peer-to-peer educator for all 3 medication adherence sessions. This student was trained by TUC College of Pharmacy faculty (E.C., S.D., E.J.I.) on how to deliver the program. The program included a presentation used with permission from the AMA Steps Forward Medication Adherence module and a second presentation on practical approaches to medication adherence. ${ }^{15}$ The second presentation described strategies to identify and assess medication nonadherence, along with solutions to tailor treatment plans.

\section{Statistical Analysis}

STATA statistical software version 14 was used. Descriptive statistics were used to summarize demographics and report frequency distributions of survey responses. Statistical comparisons between preprogram and postprogram survey responses on knowledge were made using a paired 2-tailed $t$ test for mean scores and the McNemar test for individual questions. The Wilcoxon signed-rank test was used to compare preprogram and postprogram survey responses on confidence and attitudes concerning the medication adherence program. $P<.05$ was considered to be statistically significant. Based on a sample size calculation with $\alpha$ set at .05 and an SD set at $15 \%$, a total of 73 participants would be required for the pilot study to achieve a power of .80 to detect a $20 \%$ difference in mean knowledge scores.

\section{Results}

Of the 135 osteopathic medical students invited, 23 participated in and completed the study (response rate, $17.0 \%$ ). Demographic characteristics are presented in Table 1. The mean (SD) age of participants was 25.8 (2.1) years. Thirteen students $(56.5 \%)$ were male. Concerning race/ethnicity, a majority of the respondents identified as Asian or Pacific Islander (15 [65.2\%]).

Medical students' performance on medication adherence knowledge questions before and after the program are presented in Table 2. Mean (SD) medication

\section{Table 1.}

Peer-to-Peer Medication Adherence Education Program: Participant Characteristics

\begin{tabular}{lc} 
Characteristic & $\begin{array}{c}\text { Participants } \\
(\mathbf{N}=\mathbf{2 3})\end{array}$ \\
\hline Age, y, mean (SD) & $25.8(2.1)$ \\
\hline Race/Ethnicity, No. (\%) & $15(65.2)$ \\
\hline Asian or Pacific Islander & $7(30.4)$ \\
\hline White & $1(4.3)$ \\
\hline Other & $13(54.5)$ \\
\hline Gender, No. (\%) & $10(43.5)$ \\
\hline Male & 0 \\
\hline Female & 0
\end{tabular}

Exposure to Medication

Adherence, No. (\%)

\begin{tabular}{ll}
\hline Received formal training & 0 \\
\hline $\begin{array}{l}\text { Educated patients on medication } \\
\text { adherence in past } 12 \text { months }\end{array}$ & $3(13.0)$ \\
\hline
\end{tabular}


Table 2.

Peer-to-Peer Medication Adherence Education Program: Respondent's Knowledge on Medication Adherence $(\mathbf{N}=\mathbf{2 3})^{\mathbf{a}}$

\begin{tabular}{|c|c|c|c|}
\hline Question & $\begin{array}{l}\text { Preprogram Survey } \\
\text { Correct Responses, } \\
\text { No. (\%) }\end{array}$ & $\begin{array}{c}\text { Postprogram Survey } \\
\text { Correct Responses, } \\
\text { No. (\%) }\end{array}$ & $\begin{array}{c}P \\
\text { Value }^{b}\end{array}$ \\
\hline $\begin{array}{l}\text { If understanding the meaning of medication } \\
\text { adherence is vital, which statement is correct? }\end{array}$ & $23(100)$ & $23(100)$ & $>.99$ \\
\hline $\begin{array}{l}\text { The receptionist at Everest General offers a patient } \\
\text { a pre-visit questionnaire at check-in that includes } \\
\text { questions about his/her medication usage. This is } \\
\text { a standard step for check-in with the hopes that } \\
\text { this will save time for the practice, as well as, } \\
\text { notify the physician to the patient's medication } \\
\text { routine. This standard questionnaire routine is an } \\
\text { attempt to do which of the following? }\end{array}$ & $16(69.6)$ & $18(78.3)$ & .500 \\
\hline $\begin{array}{l}\text { Which of the following is the top reason for } \\
\text { intentional medication nonadherence? }\end{array}$ & $7(30.4)$ & $19(82.6)$ & .002 \\
\hline $\begin{array}{l}\text { In order to encourage medication adherence, there } \\
\text { are ways to simplify a patient's medication } \\
\text { regimen. Which of the following is the best way to } \\
\text { increase adherence? }\end{array}$ & $23(100)$ & $23(100)$ & $>.99$ \\
\hline $\begin{array}{l}\text { The "teach-back" method is a method for a } \\
\text { physician to see if the patient understands the } \\
\text { treatment plan. Which of the following describes } \\
\text { the "teach-back" method? }\end{array}$ & $20(87.0)$ & $23(100)$ & .250 \\
\hline
\end{tabular}

a The medication adherence materials and AMA Steps Forward content were developed by and are provided with permission from the American Medical Association. For more innovative practice transformation strategies that can help your organization achieve the quadruple aim, visit www.stepsforward.org.

b Significant at $P<.05$.

adherence knowledge scores improved from $77.4 \%$ $(17.4 \%)$ to $92.2 \%(9.98 \%)$ after the program $(P<.001)$. Of the 5 knowledge questions, students showed the greatest improvement on the question querying the top reason (cost) for intentional medication nonadherence $(P=.002$; Table 2).

Medical students' confidence in medication adherence before and after the program are presented in Table 3. After the program, medical students' confidence in medication adherence increased for all 7 questions. Medical students' attitudes toward medication adherence are presented in Table 4. Improved attitudes were also noted in 8 of 10 postprogram survey responses when compared with preprogram survey responses.
Medical students' attitudes toward the peer-to-peer medication adherence program are presented in Table 5. Twenty-two students would recommend this educational program and 23 planned to implement the medication adherence skills learned in the program with future patients. Twenty-three students viewed the peer-to-peer format as an effective way to provide medication adherence education, and 22 thought that the format promoted interprofessional collaboration.

\section{Discussion}

This pilot study demonstrated that a 30-minute peer-to-peer teaching program led by a third-year 
Table 3.

Peer-to-Peer Medication Adherence Education Program: Respondent's Confidence in Medication Adherence (N=23)

\begin{tabular}{|c|c|c|c|c|c|c|c|c|c|}
\hline \multirow[b]{2}{*}{ Item } & \multicolumn{4}{|c|}{ Preprogram Survey, No. (\%) } & \multicolumn{4}{|c|}{ Postprogram Survey, No. (\%) } & \multirow[b]{2}{*}{$\begin{array}{c}P \\
\text { Value }^{\mathrm{a}}\end{array}$} \\
\hline & $\begin{array}{c}\text { Very } \\
\text { Confident }\end{array}$ & $\begin{array}{l}\text { Moderately } \\
\text { Confident }\end{array}$ & $\begin{array}{l}\text { Somewhat } \\
\text { Confident }\end{array}$ & $\begin{array}{c}\text { Not } \\
\text { Confident }\end{array}$ & $\begin{array}{c}\text { Very } \\
\text { Confident }\end{array}$ & $\begin{array}{l}\text { Moderately } \\
\text { Confident }\end{array}$ & $\begin{array}{l}\text { Somewhat } \\
\text { Confident }\end{array}$ & $\begin{array}{c}\text { Not } \\
\text { Confident }\end{array}$ & \\
\hline $\begin{array}{l}\text { Describe the scope of } \\
\text { medication } \\
\text { nonadherence (ie, } \\
\text { forms of nonadherence } \\
\text { and how common they } \\
\text { are)? }\end{array}$ & $1(4.3)$ & $4(17.4)$ & $8(34.8)$ & $11(47.8)$ & $11(47.8)$ & $9(39.1)$ & $3(13.0)$ & 0 & $<.001$ \\
\hline $\begin{array}{l}\text { Discuss the health } \\
\text { effects of medication } \\
\text { nonadherence? }\end{array}$ & $1(4.3)$ & $9(39.1)$ & $12(52.2)$ & $1(4.3)$ & $6(26.1)$ & $14(60.9)$ & $3(13.0)$ & 0 & $<.001$ \\
\hline $\begin{array}{l}\text { Describe the factors } \\
\text { that may contribute to } \\
\text { non-adherence? }\end{array}$ & $1(4.3)$ & $7(30.4)$ & $12(52.2)$ & $3(13.0)$ & $15(65.2)$ & $8(34.8)$ & 0 & 0 & $<.001$ \\
\hline $\begin{array}{l}\text { Discuss the role of } \\
\text { health literacy in } \\
\text { medication use? }\end{array}$ & $2(8.7)$ & $6(26.1)$ & $8(34.8)$ & $7(30.4)$ & $4(17.4)$ & $18(78.3)$ & $1(4.3)$ & 0 & $<.001$ \\
\hline $\begin{array}{l}\text { Assess patients' } \\
\text { medication adherence? }\end{array}$ & 0 & $6(26.1)$ & $8(34.8)$ & $9(39.1)$ & $6(26.1)$ & $12(52.2)$ & $5(21.7)$ & 0 & $<.001$ \\
\hline $\begin{array}{l}\text { Counsel patients (in } \\
\text { general) about } \\
\text { medication use? }\end{array}$ & 0 & $9(39.1)$ & $10(43.5)$ & $4(17.4)$ & $6(26.1)$ & $14(60.9)$ & $3(13.0)$ & 0 & $<.001$ \\
\hline $\begin{array}{l}\text { Counsel low-literacy } \\
\text { patients (specifically) } \\
\text { about medication use? }\end{array}$ & 0 & $5(21.7)$ & $12(52.2)$ & $6(26.1)$ & $6(26.1)$ & $13(56.5)$ & $4(17.4)$ & 0 & $<.001$ \\
\hline
\end{tabular}

a Significant at $P<.05$.

pharmacy student was effective in improving medical students' knowledge, confidence, and attitudes regarding medication adherence. The peer-to-peer teaching format was viewed as effective and enhanced interprofessional student collaboration.

The finding that medical students in the current study reported no formal training on medication adherence before this intervention is consistent with findings in studies among medical residents. ${ }^{7,16}$ Kripalani et al ${ }^{7}$ found that first-year medical residents were more likely to report receiving little to no training on medication adherence counseling when compared with secondand third-year medical residents. This finding suggests that there is a gap in medical education curricula on this topic.
To fill this gap, some institutions have added a medication adherence workshop into the medical residency training curriculum. ${ }^{7,16}$ Kripalani et $\mathrm{al}^{7}$ provided a 2-hour medication adherence counseling workshop led by internal medicine physician faculty to first-, second-, and third-year internal medicine residents. ${ }^{7}$ Similarly, Weiden and Rao ${ }^{16}$ developed a medication adherence training curriculum for third- and fourth-year psychiatry residents. This curriculum was covered in 4 classes that ran 90 minutes each for a total of 6 hours of didactic time. Both programs encompassed similar content, including definitions of nonadherence, prevalence of nonadherence, strategies to assess adherence, and interventions to address adherence. ${ }^{7,16}$ Although medication adherence workshops during residency 
Table 4.

Peer-to-Peer Medication Adherence Education Program: Respondent's Attitudes Toward Medication Adherence $(\mathbf{N}=23)$

\begin{tabular}{|c|c|c|c|c|c|c|c|c|c|}
\hline \multirow[b]{2}{*}{ Item } & \multicolumn{4}{|c|}{ Preprogram Survey, No. (\%) } & \multicolumn{4}{|c|}{ Postprogram Survey, No. (\%) } & \multirow[b]{2}{*}{$\begin{array}{c}P \\
\text { Value }^{a}\end{array}$} \\
\hline & $\begin{array}{l}\text { Strongly } \\
\text { Agree }\end{array}$ & Agree & Disagree & $\begin{array}{l}\text { Strongly } \\
\text { Disagree }\end{array}$ & $\begin{array}{c}\text { Strongly } \\
\text { Agree }\end{array}$ & Agree & Disagree & $\begin{array}{l}\text { Strongly } \\
\text { Disagree }\end{array}$ & \\
\hline $\begin{array}{l}\text { It is not a health care } \\
\text { provider's role to } \\
\text { counsel patients about } \\
\text { medication adherence. }\end{array}$ & $1(4.3)$ & $1(4.3)$ & $7(30.4)$ & $15(65.2)$ & 0 & 0 & $4(17.4)$ & $19(82.6)$ & .026 \\
\hline $\begin{array}{l}\text { I am adequately skilled } \\
\text { to provide adherence } \\
\text { counseling. }\end{array}$ & 0 & $6(26.1)$ & $13(56.5)$ & $4(17.4)$ & $2(8.7)$ & $15(65.2)$ & $6(26.1)$ & 0 & $<.001$ \\
\hline $\begin{array}{l}\text { I do not have enough } \\
\text { time to provide } \\
\text { adherence counseling. }\end{array}$ & 0 & $4(17.4)$ & 17 (73.9) & $3(13.0)$ & 0 & 0 & $14(60.9)$ & $9(39.1)$ & .003 \\
\hline $\begin{array}{l}\text { Adherence counseling } \\
\text { does not interest me. }\end{array}$ & 0 & $2(8.7)$ & $13(56.5)$ & $9(39.1)$ & 0 & 0 & $10(43.5)$ & $13(56.5)$ & .057 \\
\hline $\begin{array}{l}\text { I am confident in my } \\
\text { ability to determine } \\
\text { when patients are not } \\
\text { taking medications as } \\
\text { prescribed. }\end{array}$ & 0 & $6(26.1)$ & $16(69.6)$ & $1(4.3)$ & $2(8.7)$ & $17(73.9)$ & $4(17.4)$ & 0 & $<.001$ \\
\hline $\begin{array}{l}\text { I do not know enough } \\
\text { about medications to } \\
\text { explain them to my } \\
\text { patients. }\end{array}$ & $1(4.3)$ & $15(65.2)$ & $7(30.4)$ & 0 & $2(8.7)$ & $9(39.1)$ & $11(47.8)$ & $1(4.3)$ & .148 \\
\hline $\begin{array}{l}\text { I feel unaware of the } \\
\text { cost of medications. }\end{array}$ & $7(30.4)$ & $11(47.8)$ & $5(21.7)$ & 0 & $2(8.7)$ & $10(43.5)$ & $8(34.8)$ & $3(13.0)$ & .014 \\
\hline $\begin{array}{l}\text { Cost is an important } \\
\text { consideration when } \\
\text { making prescribing } \\
\text { choices. }\end{array}$ & $16(69.6)$ & $7(30.4)$ & 0 & 0 & $23(100)$ & 0 & 0 & 0 & .008 \\
\hline $\begin{array}{l}\text { I prefer to prescribe } \\
\text { brand-name over } \\
\text { generic drugs. }\end{array}$ & 0 & $2(8.7)$ & $14(60.9)$ & $8(34.8)$ & $1(4.3)$ & $1(4.3)$ & $2(8.7)$ & $20(87.0)$ & .007 \\
\hline $\begin{array}{l}\text { Adherence to a } \\
\text { prescribed regimen is } \\
\text { primarily the } \\
\text { responsibility of the } \\
\text { patient. }\end{array}$ & $3(13.0)$ & $8(34.8)$ & $7(30.4)$ & $5(21.7)$ & 0 & $8(34.8)$ & $8(34.8)$ & $7(30.4)$ & .047 \\
\hline
\end{tabular}

a Significant at $P<.05$.

programs can fill a gap in education, medical students may benefit from medication adherence education before their clinical rotations.
From an accreditation perspective, the medication adherence program may contribute to multiple competencies for both pharmacy students and osteopathic 
Table 5.

Respondent's Attitudes on Peer-to-Peer Medication Adherence Education Program ( $\mathbf{N}=23$ )

\begin{tabular}{|c|c|c|c|c|}
\hline \multirow[b]{2}{*}{ Item } & \multicolumn{4}{|c|}{ Postprogram Survey No. (\%) } \\
\hline & $\begin{array}{c}\text { Strongly } \\
\text { Agree }\end{array}$ & Agree & Disagree & $\begin{array}{l}\text { Strongly } \\
\text { Disagree }\end{array}$ \\
\hline $\begin{array}{l}\text { I would recommend this educational session to other } \\
\text { health professionals }\end{array}$ & $11(47.8)$ & $11(47.8)$ & $1(4.3)$ & 0 \\
\hline $\begin{array}{l}\text { I plan to implement the medication adherence skills I } \\
\text { learned today with future patients }\end{array}$ & $12(52.2)$ & $11(47.8)$ & 0 & 0 \\
\hline $\begin{array}{l}\text { I think the peer-to-peer format is an effective way to } \\
\text { provide education about medication adherence }\end{array}$ & $10(43.5)$ & $13(56.5)$ & 0 & 0 \\
\hline $\begin{array}{l}\text { I think that this type of peer-to-peer lecture promotes } \\
\text { collaboration among health professionals }\end{array}$ & $15(65.2)$ & $7(30.4)$ & $1(4.3)$ & 0 \\
\hline \multicolumn{5}{|l|}{ As a result of this educational session: } \\
\hline My opinion of pharmacists has improved & $8(34.8)$ & $14(60.9)$ & $1(4.3)$ & 0 \\
\hline $\begin{array}{l}\text { I learned how pharmacists can help us advocate for our } \\
\text { patients }\end{array}$ & $11(47.8)$ & $12(52.2)$ & 0 & 0 \\
\hline $\begin{array}{l}\text { I am more likely to consult with pharmacists about } \\
\text { medication adherence }\end{array}$ & $12(52.2)$. & $11(47.8)$ & 0 & 0 \\
\hline $\begin{array}{l}\text { I am more likely to consult with pharmacists about drug } \\
\text { selection }\end{array}$ & $12(52.2)$ & $10(43.5)$ & $1(4.3)$ & 0 \\
\hline I am more likely to consult with pharmacists about drug costs & $13(56.5)$ & $9(39.1)$ & $1(4.3)$ & 0 \\
\hline $\begin{array}{l}\text { I am more likely to consult with pharmacists about drug } \\
\text { formularies }\end{array}$ & $14(60.9)$ & $8(34.8)$ & $1(4.3)$ & 0 \\
\hline $\begin{array}{l}\text { I am more likely to consult with pharmacists about insurance } \\
\text { plans }\end{array}$ & $12(52.2)$ & $9(39.1)$ & $2(8.7)$ & 0 \\
\hline
\end{tabular}

medical students. Osteopathic core competencies are a crucial element of the 2019 Commission on Osteopathic College Accreditation curriculum standard. ${ }^{17,18}$ The American Association of Colleges of Osteopathic Medicine identified several performance indicators to meet these 7 core competencies for medical students. ${ }^{19}$ One of the performance indicators directly addresses the ability to "describe patient, physician, and system barriers to successfully negotiated treatment plans and patient adherence." ${ }^{19}$ Interprofessional education for collaborative practice is also defined as a core element under the same standard. ${ }^{17,18}$ The current educational program provides a learning experience that introduces osteopathic medical students to medication adherence and pharmacist roles within the health care team. Increased knowledge of pharmacist roles helps fulfill an Interprofessional Education Collaborative competency regarding the roles and responsibilities of multiple health care professions. ${ }^{20}$ Both the Center for Advancement of Pharmaceutical Education 2013 Educational Outcomes and the Accreditation Council of Pharmacy Education Standards and Guidance also emphasize the importance of understanding interprofessional roles to promote interprofessional collaboration. $^{21-23}$

In the current study, the peer-to-peer program was able to increase medical students' confidence in 
assessing and addressing medication adherence. This finding coincides with study results of Kripalani et al, ${ }^{7}$ which demonstrated that a medication adherence counseling workshop helped improve internal medicine residents' confidence to perform adherence counseling. Furthermore, Kripalani et $\mathrm{al}^{7}$ found that this workshop significantly improved self-reported medication adherence counseling behaviors for internal medicine residents after 1 month. These behaviors included assessing patients' understanding of how to take their medications, barriers to adherence, and strategies to tailor the patient's regimen. ${ }^{7}$ Although follow-up data on behavior changes or patient outcomes were not obtained in the current study, our postprogram survey results revealed that all participants expected to implement the skills learned from this program in the future. Medical students in this study recognized the importance of being involved in medication adherence as future health care professionals. These positive results are particularly encouraging to enhance future practice behavior.

The program was effective in increasing osteopathic medical students' knowledge of medication adherence. Lai et $\mathrm{al}^{24}$ used a similar format to evaluate the impact of a 1- to 2-hour peer-to-peer lecture on Medicare Part D. The authors reported an increase in self-rated knowledge on Medicare Part D and intention of the students to collaborate with pharmacists as a result of this intervention.

Participants agreed that the peer-to-peer format was an effective learning tool. These results are congruent with those of Lipton et al, ${ }^{14}$ who found that medical students, nursing students, and medical residents viewed the peer-to-peer teaching format as an effective method to provide education on Medicare Part D. Similar to our study, the authors ${ }^{14}$ reported that as a result of a peer-to-peer teaching session led by a third-year pharmacy student, students reported increased confidence in pharmacists' abilities and greater likelihood to consult with pharmacists on multiple medication-related issues. These issues included concerns about medication selection, medication costs, formularies, drug policy, and insurance plans. Lehrer et $\mathrm{al}^{25}$ also revealed that after an interprofessional peer-to-peer session by second-year medical students, pharmacy and medical students identified a greater need for cooperation with other health care professions. These results demonstrate an effective approach to promote interprofessional peer-to-peer teaching and to introduce students to the roles of different health care professions.

There were several limitations to this study that should be addressed. First, given the low response rate, the results may not be reflective of the entire class. The study did not reach the required sample size of 73 participants needed to achieve $80 \%$ power. The low rate of participation may have been multifactorial: the program was not mandatory, and the sessions were held at the end of the didactic year, close to final examinations. It is unclear whether student disinterest, student burnout, or other factors may have also caused a low response rate. Future studies should focus on assessing whether these results are reproducible in a larger sample size.

A second limitation was that this study took place at a single institution, which may limit generalizability. Third, about $65 \%$ of participants identified as Asian or Pacific Islander. According to the American Association of Colleges of Osteopathic Medicine, this race/ethnicity only represented about $23 \%$ of the national population of first-year osteopathic medical students in the 2018-2019 academic year. ${ }^{26}$ Fourth, we did not assess whether the outcomes of this teaching format led to long-term changes in behavior and attitudes toward medication adherence and interprofessional collaboration. However, we still found these short-term results important. Previous educational studies have found value measuring outcomes in a similar manner. ${ }^{7,14,24}$ Future studies may wish to explore the long-term outcomes and effectiveness of this peer-to-peer medication adherence program on medical students from various programs across the United States. 


\section{Conclusion}

A 30-minute peer-to-peer program led by a third-year pharmacy student improved first-year medical students' knowledge, confidence, and attitudes concerning medication adherence. Having health care professional students provide peer-to-peer teaching on topics specific to their education may increase understanding of interprofessional roles and add value to the osteopathic medical education curriculum. Future health care professional programs may consider adopting this educational activity to enhance interprofessional learning and collaboration.

\section{Acknowledgements}

We thank Jay H. Shubrook, DO, and Clipper Young, PharmD, $\mathrm{MPH}, \mathrm{CDE}$, BC-ADM, for helping us coordinate osteopathic medical student schedules for the 3 medication adherence sessions delivered. We also thank Sunil Kripalani, MD, MSc, for graciously allowing us to use and modify a survey.

\section{Author Contributions}

All authors provided substantial contributions to conception and design, acquisition of data, or analysis and interpretation of data; all authors drafted the article or revised it critically for important intellectual content; all authors gave final approval of the version of the article to be published; and all authors agree to be accountable for all aspects of the work in ensuring that questions related to the accuracy or integrity of any part of the work are appropriately investigated and resolved.

\section{References}

1. Sabaté E. Adherence to Long-Term Therapies: Evidence for Action. Geneva: World Health Organization; 2003.

2. Osterberg L, Blaschke T. Adherence to medication. N Engl J Med. 2005;353(5):487-497. doi:10.1056/NEJMra050100

3. McCarthy R. The price you pay for the drug not taken. Bus Health. 1998;16(10):27-28, 30, 32-23.

4. Bokhour BG, Berlowitz DR, Long JA, Kressin NR. How do providers assess antihypertensive medication adherence in medical encounters? J Gen Intern Med. 2006;21(6):577-583. doi:10.1111/ j.1525-1497.2006.00397.x

5. Wilson IB, Schoen C, Neuman P, et al. Physician-patient communication about prescription medication nonadherence: a 50-state study of America's seniors. J Gen Intern Med. 2007;22 (1):6-12. doi:10.1007/s11606-006-0093-0

6. Scherwitz L, Hennrikus D, Yusim S, Lester J, Vallbona C. Physician communication to patients regarding medications. Patient Educ Couns. 1985;7(2):121-136. doi:10.1016/0738-3991(85)90003-5

7. Kripalani S, Osborn CY, Vaccarino V, Jacobson TA. Development and evaluation of a medication counseling workshop for physicians: can we improve on 'take two pills and call me in the morning'? Med Educ Online. 2011;16. doi:10.3402/meo.v16i0.7133

8. Singla DL, MacKinnon GE III, MacKinnon KJ, Younis W, Field B. Interdisciplinary approach to teaching medication adherence to pharmacy and osteopathic medical students. J Am Osteopath Assoc. 2004;104(3):127-132.

9. O'Connor DM, Savageau JA, Centerbar DB, Wamback KN, Ingle JS, Lomerson NJ. Lesson in a pill box: teaching about the challenges of medication adherence. Fam Med. 2009;41(2):99-104.

10. Kastrissios H, Flowers NT, Blaschke TF. Introducing medical students to medication noncompliance. Clin Pharmacol Ther. 1996;59 (5):577-582. doi:10.1016/S0009-9236(96)90186-1

11. Sutton EL, Transue ER, Comes S, Paauw DS. Placebo HAART regimen as a method for teaching medication adherence issues to students. J Gen Intern Med. 2005;20(6):541-545. doi:10.1111/ j.1525-1497.2005.0096.x

12. Rickles NM, MacLean LG, Hess $\mathrm{K}$, et al. Teaching medication adherence in US colleges and schools of pharmacy. Am J Pharm Educ. 2012;76(5):79. doi:10.5688/ajpe76579

13. Barr H. Interprofessional Education : Today, Yesterday And Tomorrow: A Review. London, England: Learning and Teaching Support Network; 2002.

14. Lipton HL, Lai CJ, Cutler TW, Smith AR, Stebbins MR. Peer-to-peer interprofessional health policy education for Medicare part D. Am J Pharm Educ. 2010;74(6):102. doi:10.5688/aj7406102

15. Medication Adherence: Improve Patient Outcomes and Reduce Costs. American Medical Association website. https://edhub.ama-assn.org/ steps-forward/module/2702595. Published 2015. Accessed February 12, 2020.

16. Weiden PJ, Rao N. Teaching medication compliance to psychiatric residents: placing an orphan topic into a training curriculum. Acad Psychiatry. 2005;29(2):203-210. doi:10.1176/appi. ap.29.2.203

17. Commission on Osteopathic College Accreditation. Accreditation of Colleges of Osteopathic Medicine: COM Continuing Accreditation Standards. Chicago, IL: American Osteopathic Association; 2019.

18. Commission on Osteopathic College Accreditation. Accreditation of Colleges of Osteopathic Medicine: COM New \& Developing Accreditation Standards. Chicago, IL: American Osteopathic Association; 2019.

19. Osteopathic Core Competencies for Medical Students. Bethesda, MD American Association of Colleges of Osteopathic Medicine; 2012.

20. Core Competencies for Interprofessional Collaborative Practice: 2016 Update. Interprofessional Education Collaborative; 2016.

21. Accreditation Council for Pharmacy Education: Accreditation Standards and Key Elements for the Professional Program in Pharmacy Leading to the Doctor of Pharmacy Degree. Chicago, IL: Accreditation Council for Pharmacy Education; 2015.

22. Accreditation Council for Pharmacy Education: Guidance for the Accreditation Standards and Key Elements for the Professional Program in Pharmacy Leading to the Doctor of Pharmacy Degree. Chicago, IL: Accreditation Council for Pharmacy Education; 2015.

23. Medina MS, Plaza CM, Stowe CD, et al. Center for the Advancement of Pharmacy Education 2013 educational outcomes. Am J Pharm Educ. 2013;77(8):162. doi:10.5688/ajpe778162 
24. Lai CJ, Smith AR, Stebbins MR, Cutler TW, Lipton HL. Promoting interprofessional collaboration: pharmacy students teaching current and future prescribers about Medicare Part D. J Manag Care Pharm. 2011;17(6):439-448. doi:10.18553/jmcp.2011.17.6.439

25. Lehrer MD, Murray S, Benzar R, et al. Peer-led problem-based learning in interprofessional education of health professions students. Med Educ Online. 2015;20:28851. doi:10.3402/meo. v20.28851

26. 2018-19 Osteopathic Medical College First-Year Enrollment by Gender and Race/Ethnicity. Bethesda, MD: American Association of Colleges of Osteopathic Medicine; 2019.

(c) 2020 American Osteopathic Association

\section{@TheJAOA on Twitter}

Follow us at http://www.twitter.com/TheJAOA to get involved and stay connected with updates, highlights, and conversations about osteopathic medical research. 